\title{
Are Your History Slides Effective?
}

\author{
Ralph McKay, Ed.D. ${ }^{*}$ \\ ${ }^{1}$ Lecturer \& Supervisor, Secondary Student Teachers, Laurie College of Education and College of \\ Social Sciences, San Jose State University, San Jose, California
}

Received: May 23, 2021

Accepted: June 11, 2020

Online Published: July 6, 2021

doi:10.22158/wjeh.v3n3p38

URL: http://dx.doi.org/10.22158/wjeh.v3n3p38

\section{Introduction}

Since returning to teaching after a long career in real estate sales and marketing, I have viewed instructional materials with a keener eye. Now my high school History and University slides are closely scrutinized. As a real estate salesperson, my economic survival depended on a slide presentation. My initial meeting with a client was my only opportunity to convince them that I was the one to help them achieve their objectives. Usually, I had thirty minutes or less to accomplish this task. Thus, my presentation had to be compelling and straightforward. Fortunately, through trial and error, I stumbled upon a format that worked for me and would serve me well in the future. It replaced aclient's blank expression with an engaging smile. My presentation proved successful, and I was able to earn my livelihood.

When I returned to teaching, I used my real estate experience to develop "Guidelines for Effective Historical Slides" based on "Cognitive Load Theory." My presentations improved. For example, my slides triggered more student engagement than I had previously known. Many students volunteered that they enjoyed learning the subject matter. After reviewing colleague's slides and those of my student teachers, I realized that, in many cases, their slides included too much information "and were improperly formatted, thus, impeding student learning.

Why were some teachers producing slides which impede learning? The simple answer is that most teachers receive little training in slide preparation. In most cases, high school history teachers are using slides prepared by their department colleagues. Following mandated state common core guidelines and district curriculum guides, each department creates or revises its instructional units at the beginning of the school year. Teachers are responsible for one or more units, including a day-to-day lesson calendar, supporting materials, and presentation slides. All units are then posted on a master calendar for department members to see; however, most teachers do not review slide presentations before presenting them. If they do, it is a cursory review caused by a lack of time. Consequently, students read silently while the teacher reads the slide aloud, resulting in a dull lesson and disengaged students. 
What complicates the production of effective slides is that many teachers do not understand a slide's purpose. Slides should contain bullet points, not sentences. They present essentialide as easily remembered by students and highlight a teacher's main points. Slides are aids, not lecture notes. Frequently, this is not the case. Observers often see teachers reading their presentation verbatim from slides as students attempt to follow along by reading silently. Additionally, many teachers do not know how to display information for maximum effectiveness. As the foundation of most lessons, instructional slides should receive a close review, but they do not.

\section{Cognitive Load Theory}

"Cognitive Load Theory" is the foundation of my guide and the subject of numerous research articles. Unfortunately, it is often overlooked by instructors preparing educational materials. The theory suggests that too much information may overload a student's memory system and impede learning. Cynthia Brame's excellent article, "Effective Educational Video's," reinforces the importance of "Cognitive Load Theory" in her discussion of educational videos. Brame (2015) states, "One of the primary considerations when constructing educational material including video, is cognitive load" ( $p$. 1). Since the preparation of a slide has many similarities to video production, particularly in selecting information that students must process, her cognitive load discussion is relevant. Brame's article includes an in-depth discussion of three cognitive load components: intrinsic, germane, and extraneous loads. For our purpose, we focus on the extraneous load. Extraneous load is the information the teacher includes on their slide. Brame's article should help those interested in learning more about intrinsic and germane load as well as "Cognitive Load Theory."

Using a modification of Brame's Memory Component Chart (See page 3), we trace the sequence of steps taken by the brain to process information. Our goal is to facilitate the storage of important information in the student's Long-term Memory.

Sensory Memory is the first to receive information. Here visual and auditory sensors process text, pictures, and voice for transfer to the Working Memory. The Working Memory selects some items for encoding and transfer to Long-Term Memory and discards the rest.

"Cognitive Load Theory" suggests that visual and auditory information are processed separately and do not compete in the Working Memory, while two visual items may. For example, a picture and some text may compete against one another on a single slide for attention, creating a "Split-Attention Effect," which is difficult for the Working Memory to process. According to Chandler and Wheller (1992), "Learners are often forced to split their attention between and mentally integrate disparate sources of information (e.g., text and diagrams) before the instructional material can be rendered intelligible" (p. 233). The "Split-Attention Effect" is similar to the phenomenon of too much "eye candy" on a website, 
slang for extra graphics that compete for the viewer's attention and cause them to lose focus. This distraction impairs processing in the Working Memory and results in discarded information. We can now appreciate the critical tasks our Working Memory performs.

\section{Guidelines for Effective History Slides}

Once teachers understand the importance of "Cognitive Load Theory," they are ready to review their slides to determine if effective content is present. Using my "Guidelines for Effective History Slides" will facilitate this process. Teachers will quickly complete their reviews. By comparing their slide with my criteria, teachers will know if their aid helps or hinders student comprehension. This review usually results in pruning, re-configuring, or jettisoning some slides. Hopefully, this process also results in instructional material better suited for student learning.

\section{"Guidelines for Effective History Slides*}

- $\quad$ Make it simple.

- Use words or phrases, not sentences.

- $\quad$ Present one primary idea per slide.

- $\quad$ No more than 5 or 6 bullet-points to support the primary idea

- Use light-colored letters against a dark-colored background.

- $\quad$ Avoid multi-colors.

- Avoid professional templates; they frequently include distracting designs or colors.

- Relate pictures or graphic art to the primary idea.

- $\quad$ Use a minimum font size of 24 inches.

* The number of slides used during a presentation is of little consequence.

\section{References}

Brame, C. J. (2015). Effective educational videos. Retrieved June 20, 2020, from http://cft.vanderbilt.edu/guides-sub-pages/effective-educational-videos/.

Chandler, P., \& Sweller, J. (1992). The split-attention effect as a factor in the design of instruction. British Journal of Educational Psychology, 62, 233-246. 


\section{Memory Commonent Chart}

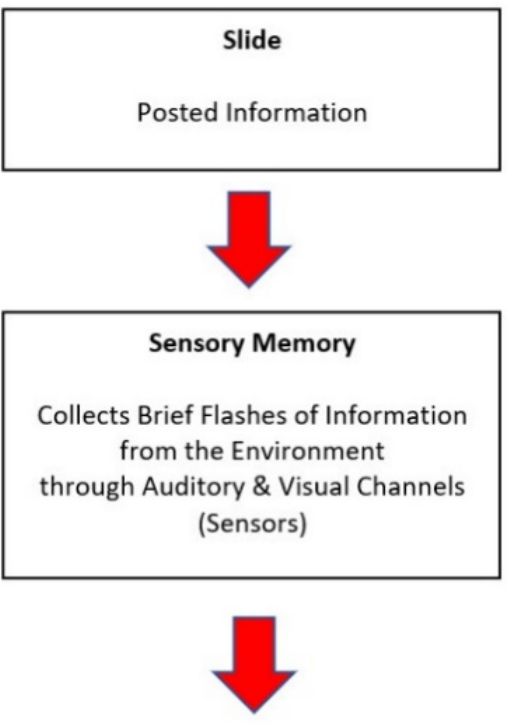

Working Memory

Information is Processed \&

Evaluated.

Limited Space Capacity

Selects \& Encodes information for

transfer to Long-term Memory.

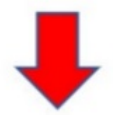

Long-term Memory Storage

Unlimited Capacity

\section{Appendix}

\section{World History Slides}

Published by SCHOLINK INC. 
Each slide has a critique followed by a suggested revision.

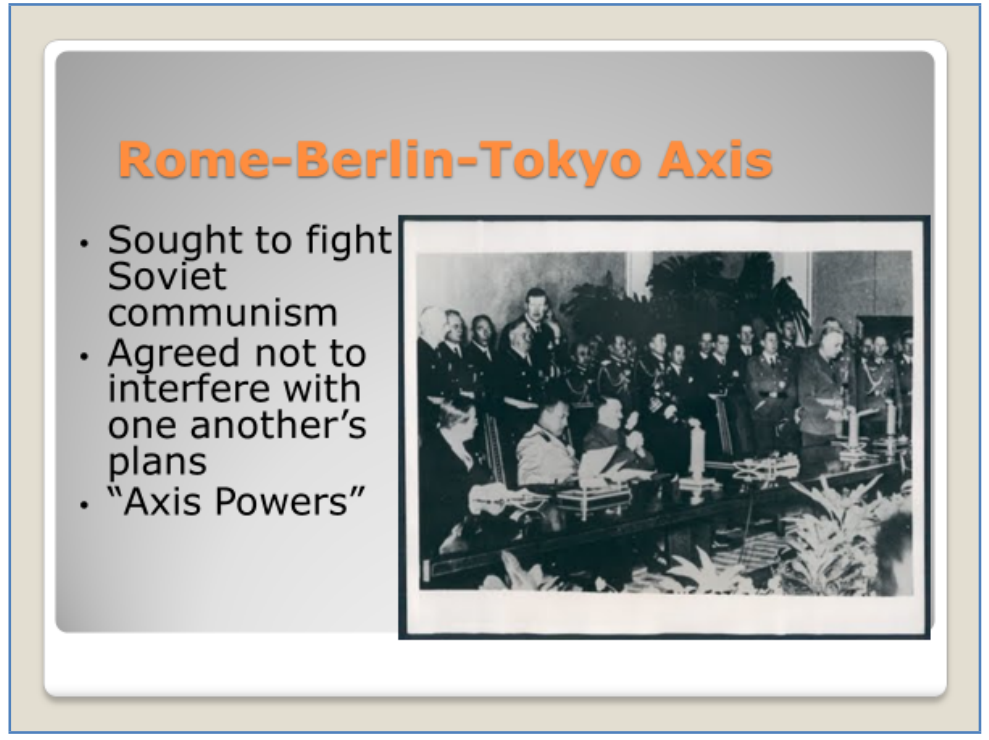

Critique: Too many ideas presented on the same slide, and darkcolored letters are used against a light-colored background

\section{Revised Slide}

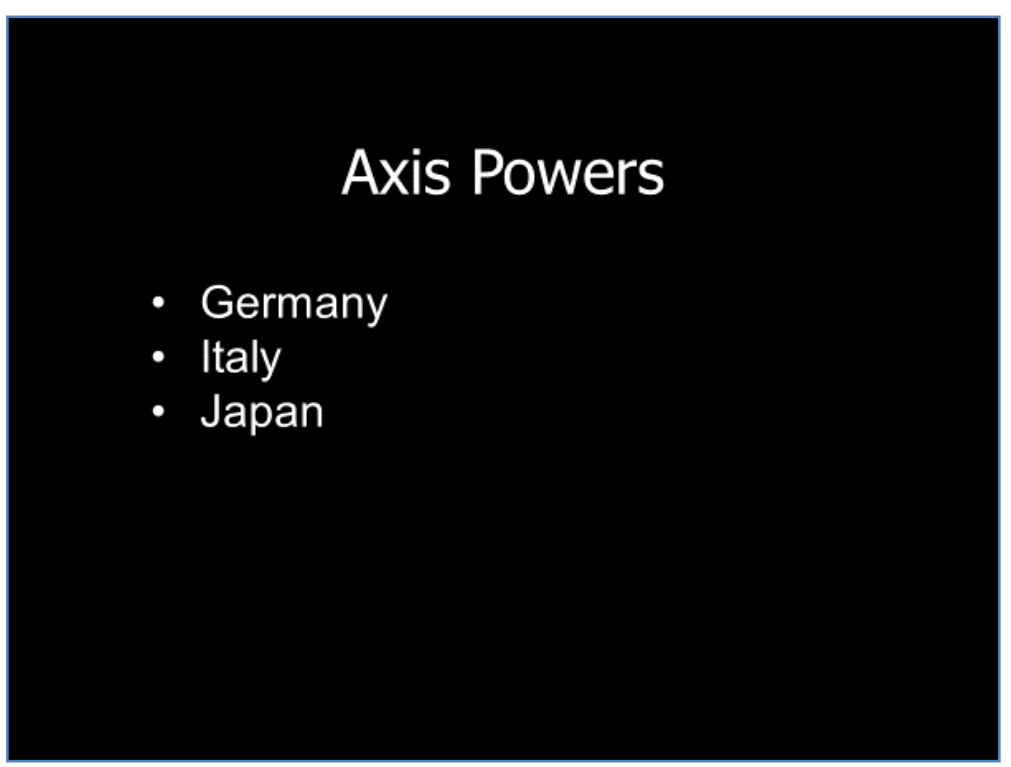




\section{Manhattan Project}

- Einstein urged FDR to establish a forum for scientific research to secure a bomb before Germany did.

- Secret project to create an American nuclear weapon - secret research \& secret testing

- Vice President (and later President) Harry Truman was not even informed of the Manhattan Project

- Employed over 100,000 people-many did not realize exactly what they were working on

- Government spent over 1 billion dollars building the bomb (some say that this was one of the reasons it was dropped - to not waste money)

Critique: Too many words and dark-colored letters are used against a light-colored background

\section{Revised Slide}

\section{Manhattan Project}

- 1939-1945

- Build an Atomic Bomb before Germany

- Secret American project

- Employed over 100,000 people in many different locations

- Government spent over \$1 Billion dollars 


\section{Ralph McKay's Biography}

I have held numerous positions in California school districts and Universities: five years as a High School English/History Teacher and Coordinator of Advanced Placement Programs in the Mountain View-Los Altos High School District, Mountain View, CA; thirteen years in the Franklin-McKinley School District (Title 1), San Jose, CA. serving as a History Teacher, Vice Principal, Principal, Director of Human Resources, Assistant Superintendent, and Superintendent; two years as a Supervisor of Intern-Teachers, University of the Pacific, Stockton, CA; and two years as an Assistant Professor of Educational Leadership at San Jose State University. I am currently a Lecturer and Supervisor of Secondary Student Teachers at San Jose State University for the Teacher Education and History Departments and teach History part-time in local high schools. 